\title{
Endometriosis in the canal of Nuck: Atypical manifestations in an unusual location
}

\author{
Patrick Cervini MD², Louis Wu MD CM FRCPC ${ }^{2}$, Robert Shenker MD MSc ${ }^{1}$, Catherine O'Blenes MD PhD ${ }^{1}$, \\ James Mahoney MD FRCSC FACS ${ }^{1}$
}

P Cervini, L Wu, R Shenker, C O’Blenes, J Mahoney. Endometriosis in the canal of Nuck: Atypical manifestations in an unusual location. Can J Plast Surg 2004;12(2):73-75.

The canal of Nuck is an embryological remnant of the processus vaginalis and has been described as a site for endometriosis seeding. Endometriosis localized to the canal of Nuck is exceedingly rare with three cases reported. The case of a 31-year-old woman with an endometrioma in the canal of Nuck, made diagnostically challenging by atypical imaging and clinical findings, is described.

Key Words: Endometrioma; Endometriosis; Inguinal canal; Magnetic resonance; Ultrasonography

$\mathrm{E}^{\mathrm{n}}$ ndometriosis is the presence of endometrial glands and stroma outside of the uterus. It has been found to occur in many different locations including the vagina, vulva, cervix, perineum, inguinal canal, urinary system, gastrointestinal tract, pulmonary structures, extremities, skin and central nervous system (1). Endometriosis within the inguinal region is rare, with approximately 40 cases reported in the world literature. It may present to plastic surgeons as a nonspecific soft tissue groin mass, or to general surgeons as an inguinal hernia. The canal of Nuck is an embryological remnant of the processus vaginalis that can remain patent, and has been described as a site for endometriosis seeding (2,3). It is a dilation of the peritoneum that accompanies the round ligament and extends from the inguinal canal into the vulva (Figure 1). Endometriosis specifically localized to the canal of Nuck is exceedingly rare and presents as a soft tissue mass in the groin.

In the present paper, a case of endometriosis of the canal of Nuck which was presented to the authors' plastic surgery service as a soft tissue mass of the groin is described. Because endometriosis is traditionally managed by gynecology services, this case underlies the need for general and plastic surgeons to be aware of this condition and how it may be differentiated preoperatively from other soft tissue masses of the groin.

\section{CASE PRESENTATION}

A healthy 31-year-old premenopausal woman presented with a mass overlying her right pubis. The mass had been present for six months and had been slowly increasing in size over that time period. The size changes were noted to concur with menses. Her past medical history was unremarkable. She denied catamenial pain at the time of presentation. Physical

\section{L'endométriose dans le canal de Nuck : Des manifestations atypiques à un foyer inhabituel}

Le canal de Nuck est un vestige embryologique du processus vaginalis et est décrit comme un foyer d'essaimage de l'endométriose. L'endométriose située dans le canal de Nuck est d'une extrême rareté, puisque trois cas ont été déclarés. Le cas d'une femme de 31 ans atteinte d'endométriose du canal de Nuck, dont le diagnostic a été compliqué par une imagerie et des observations cliniques atypiques, est présenté. examination revealed a $2 \mathrm{~cm}$ subcutaneous thickening to the right of the midline overlying the patient's right pubis, that was painful on palpation.

Sonographic examination showed a subcutaneous, welldefined hypoechoic nodule measuring $1.6 \times 1.0 \mathrm{~cm}$ (Figure 2). Sonographically guided aspiration biopsy yielded insufficient information for a diagnosis: scant cellularity, hemosiderinladen macrophages and some fibrous tissue. Contrastenhanced computed tomography of the abdomen and pelvis revealed a small, homogenous, soft tissue nodule comparable with the sonography results. Subsequently, pelvic magnetic resonance imaging (MRI) was ordered and showed an intermediate signal intensity $\mathrm{T} 1$-weighted and T2-weighted nodule with homogenous enhancement measuring $1.0 \times 1.8 \times 1.2 \mathrm{~cm}$ (Figure 3 ). The lesion was felt to be superficial to the abdominal wall musculature. No associated pelvic disease was identified. Imaging features suggested that the mass could represent inflammatory disease. No specific features of endometriosis or a neoplastic process, such as a soft tissue sarcoma, were present.

Definitive excisional biopsy of the lesion was performed. Surgical exploration revealed a $2 \times 2 \mathrm{~cm}$, brown-coloured mass encased in a sac-like structure that was in close approximation to the round ligament. Pathological examination of the specimen provided a diagnosis of endometriosis.

\section{DISCUSSION}

Endometriosis of the canal of Nuck is an extremely rare condition that presents as an inguinal mass. There are few reports of this entity published in the world literature (2-4).

The preoperative diagnosis in this case was challenging because of atypical imaging features and nondiagnostic fine

\footnotetext{
${ }^{1}$ Division of Plastic Surgery and Reconstructive Surgery, St Michael's Hospital; and ${ }^{2}$ Department of Medical Imaging, St Michael's Hospital, Toronto, Ontario

Correspondence and reprints: Dr James Mahoney, St Michael's Hospital, 30 Bond St, 4-080 Queen Wing Toronto, Ontario, M5B 1W8.

Telephone 416-864-5385, fax 416-864-5385, e-mail james.mahoney@utoronto.ca
} 


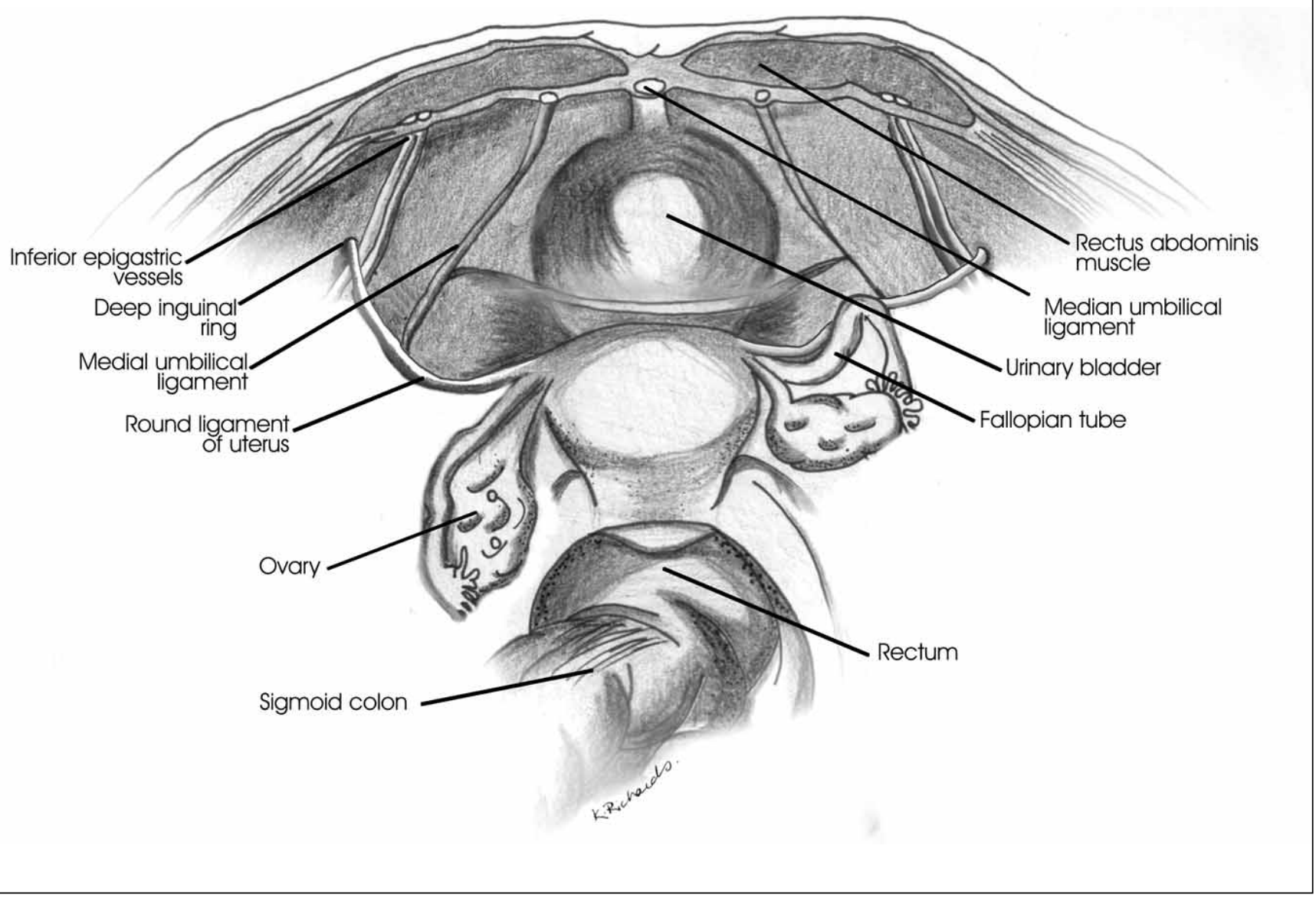

Figure 1) Course of the round ligament from lateral wall of uterine body into deep inguinal ring

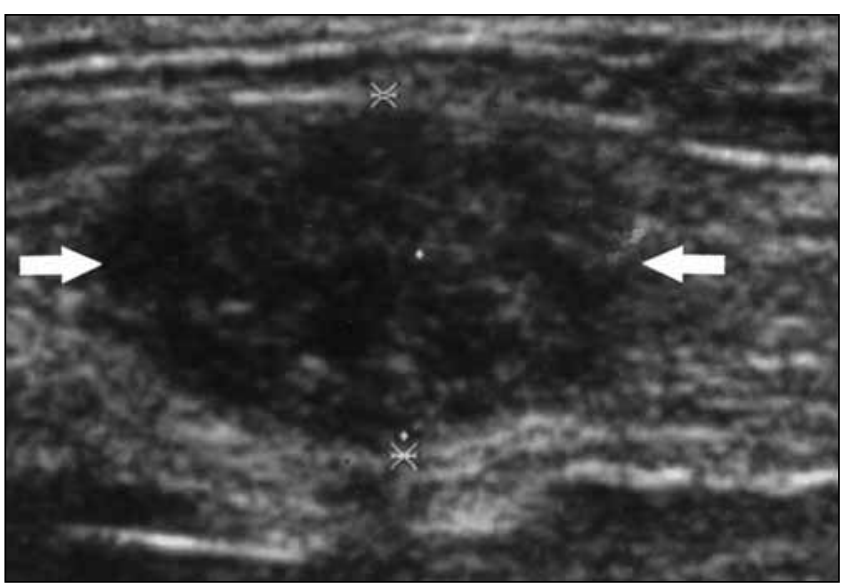

Figure 2) Transverse sonographic image over palpable nodule shows hypoechoic nodule (arrows) without definite through transmission identified in subcutaneous tissue of right lower groin

needle aspiration (FNA). In classic endometriosis, sonography and MRI are the primary diagnostic imaging tools. In our patient, sonography confirmed the presence of a focal lesion showing hypoechogenicity without through transmission. The absence of specific findings to suggest endometriosis, however, led to the need for FNA. FNA biopsy has been shown to be very accurate at distinguishing endometriosis from neoplastic considerations and inflammation (5). In our case, FNA was nondiagnostic. MRI was pursued for characterization and localization of the lesion. MRI has high sensitivity and specificity compared with other imaging modalities in the diagnosis of pelvic endometriosis. The sensitivity and specificity of MRI have been reported as high as $90 \%$ and $98 \%$, respectively, in diagnosing endometrial cysts (6). MRI in this patient, unfortunately, was nonspecific. Although inflammatory disease and endometriosis were considered, a soft tissue sarcoma could not be excluded from the differential diagnosis. Surgical excision was therefore performed.

Surgical excision is both diagnostic and therapeutic for pelvic endometriosis. Strasser and Davis (7) have shown that excision is curative and results in permanent relief of pain. There have been several case reports of malignant transformation of endometriosis within the vulva and labia, with one series reporting a malignant transformation rate of $0.7 \%$ to $1.0 \%$ (8-10).

The diagnostic dilemma in our patient could be attributed to three primary factors. First, the disease entity was in an extremely unusual location. Second, the FNA was nondiagnostic. Third, the imaging manifestations on both sonography and MRI in our patient were atypical. This case illustrates the challenges in diagnosing atypical presentations of well-recognized diseases. A palpable mass in the subcutaneous tissues of the pelvis is a nonspecific finding. However, in women at risk for endometriosis, we believe that the traditional dogma of 


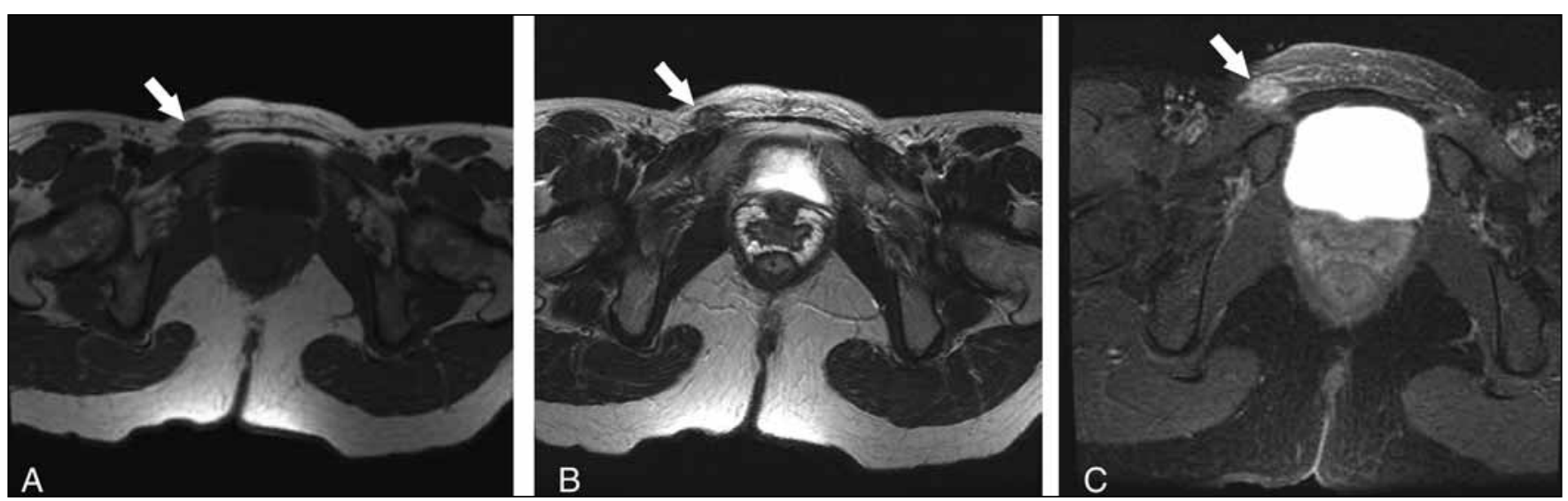

Figure 3) (A) Axillary spin echocardiography T1 and (B) fast spin echocardiography T2 showing subcutaneous homogenous intermediate signal intensity nodule on both sequences (arrows). (C) Axillary spin echocardiography gadolinium enhanced with fat saturation shows homogeneous enhancement of nodule (arrow)

uncommon manifestations of a common lesion must be considered in the differential diagnosis, as illustrated by our case of extra-pelvic endometriosis in the canal of Nuck with unusual imaging.

ACKNOWLEDGEMENTS: We would like to thank Ms Krista Richards for her skillful rendition of the round ligament and its course.

\section{REFERENCES}

1. Honore GM. Extrapelvic endometriosis. Clin Obstet Gynecol 1999;42:699-711.

2. Clausen I, Nielsen KT. Endometriosis in the groin. Int J Gynaecol Obstet 1987;25:469-71.

3. Freed KS, Granke DS, Tyre LL, Williams VL, Omert LA. Endometriosis of the extraperitoneal portion of the round ligament: US and CT findings. J Clin Ultrasound 1996;24:540-2.
4. Turpin F, Daclin PY, Karam R, et al. A case of muscular and canal of Nuck involvement by endometriosis. J Radiol 2001;82:933-5.

5. Perez-Seoane C, Vargas J, de Agustin P. Endometriosis in an inguinal crural hernia. Diagnosis by fine needle aspiration biopsy. Acta Cytol 1991;35:350-2.

6. Togashi K, Nishimura K, Kimura I, et al. Endometrial cysts: Diagnosis with MR imaging. Radiology 1991;180:73-8.

7. Strasser EJ, Davis RM. Extraperitoneal inguinal endometriosis. Am Surg 1977;43:421-2.

8. Lauslahti K. Malignant external endometriosis. A case of adenocarcinoma of umbilical endometriosis. Acta Pathol Microbiol Scand 1972;233:98-102

9. Irvin W, Pelkey T, Rice L, Andersen W. Endometrial stromal sarcoma of the vulva arising in extraovarian endometriosis: A case report and literature review. Gynecol Oncol 1998;71:313-6.

10. Mesko JD, Gates H, McDonald TW, Youmans R, Lewis J. Clear cell ('mesonephroid') adenocarcinoma of the vulva arising in endometriosis: A case report. Gynecol Oncol 1988;29:385-91. 